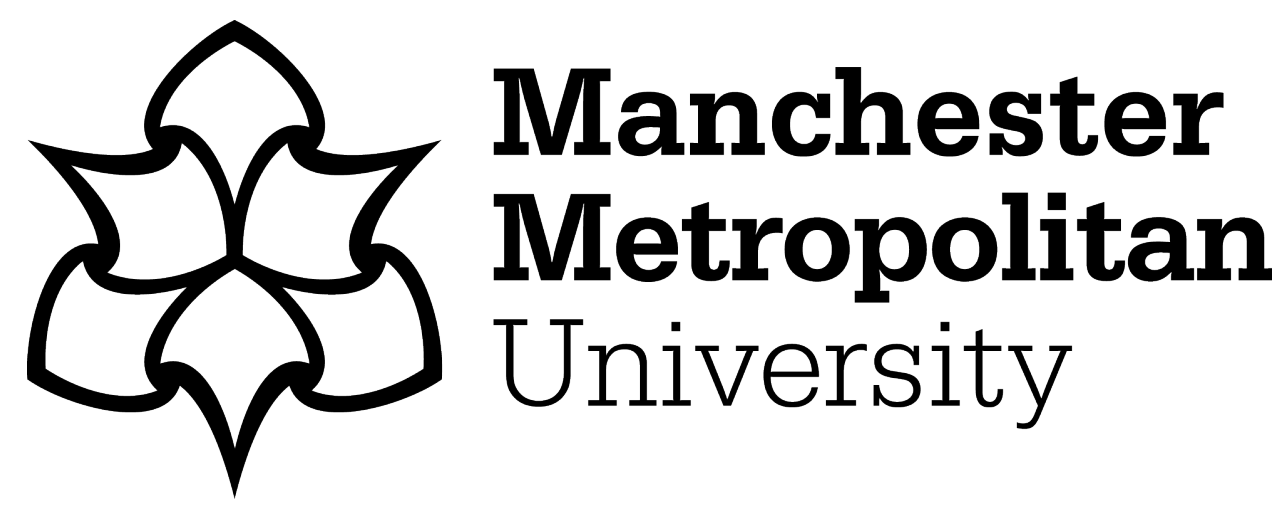

Mellado, Felipe, Wong, Phui Fung, Amano, Kinjiro, Johnson, Christopher ORCID logoORCID: https://orcid.org/0000-0003-1172-1383 and Lou, Eric CW ORCID logoORCID: https://orcid.org/0000-0001-7099-1426 (2020) Digitisation of existing buildings to support building assessment schemes: viability of automated sustainability-led design scan-to-BIM process. Architectural Engineering and Design Management, 16 (2). pp. 84-99. ISSN 1745-2007

Downloaded from: https://e-space.mmu.ac.uk/624125/

Version: Accepted Version

Publisher: Informa UK Limited

DOI: https://doi.org/10.1080/17452007.2019.1674126

Please cite the published version 


\section{Digitisation of existing buildings to support building assessment schemes: Viability of automated sustainability-led design scan-to-BIM process}

Felipe Mellado ${ }^{12}$, Phui Fung Wong ${ }^{3 *}$, Kinjiro Amano ${ }^{4}$, Christopher Johnson ${ }^{5}$, Eric C.W. Lou ${ }^{5}$

${ }^{I}$ School of Mechanical, Aerospace and Civil Engineering, Pariser Building, University of Manchester, Manchester M13 9PL, UK.

${ }^{2}$ Innovation Centre of Applied Engineering, Universidad Católica del Maule, Talca 3605, Chile.

${ }^{3}$ Department of Surveying, Lee Kong Chian Faculty of Engineering and Science, Universiti Tunku Abdul Rahman (UTAR), Sungai Long Campus, 43000 Kajang Malaysia.

${ }^{4}$ School of Electrical and Electronic Engineering, Sackville Street Building, University of Manchester, Manchester M13 9PL, UK.

${ }^{5}$ School of Engineering, John Dalton Building, Manchester Metropolitan University, Manchester MI $5 G D, U K$.

\footnotetext{
* Corresponding author. E-mail address: pfwong@utar.edu.my
} 


\title{
Digitisation of existing buildings to support building assessment schemes: Viability of automated sustainability-led design scan-to-BIM process
}

\begin{abstract}
Buildings' functional and physical characteristics can be digitally represented through Building Information Modelling (BIM) which creates a sharing platform for all stakeholders involved in the project lifecycle. The application of BIM has been studied throughout the years mainly in new buildings with less emphasis in refurbishing existing ones due to the limited availability of accurate data of the original project. However, maintaining and refurbishing existing buildings often contributes to higher risk and cost. In addition, more buildings are required to undertake building assessment schemes such as Building Research Establishment Environmental Assessment Method (BREEAM), Leadership in Energy and Environmental Design (LEED), Green Star, Green Mark, and Green Building Index (GBI) - most were not designed to assess existing buildings. In this sense, laser scanning can be used to collect existing parametric building data as point clouds, which can be developed and used for modelling of energy consumption, comfort and costing. This can be then translated back into assessment schemes. The aim of this paper is to demonstrate the process flow in the usage of laser scanning for existing buildings to support sustainability-led design by a new scan-to-BIM process.
\end{abstract}

Keywords: assessment schemes; BIM; laser scanning; refurbishment; sustainability-led design; scan-to-BIM 


\section{Introduction}

The construction industry is the major contributor to carbon emissions and global warming in the world (Raslanas et al., 2013; Huang et al., 2018). Buildings have a direct impact on the environment throughout their entire lifecycle from inception to decommission. This sector is now been targeted as a major contributor to reducing the amount of greenhouse gas (GHG) emissions (IPCC, 2007). In this sense, existing buildings are an important part of this plan if sustainability is to be achieved (Shika et al., 2014). The problem is that most of the attention is on new buildings and the current assessment schemes are, therefore, more focused on this aspect (Kamaruzzaman et al., 2019).

The United Kingdom (UK) has nearly 30 million buildings, among which approximately 28 million (including 25 million homes) require refurbishment or retrofitting $\left(\mathrm{RE}^{2}\right)$ by 2050 to meet national carbon targets (Edwards and Townsend, 2011). Hence, this will be the major work for the construction industry in the next 20 years. The main issue of $\mathrm{RE}^{2}$ is the unavailability or inaccurate building drawings, plans or blueprints (Gorse and Highfield, 2009). Without these, the $\mathrm{RE}^{2}$ project is open to a myriad of engineering unknowns and risks, causing additional concerns to health and safety, financial uncertainties and hazards. To optimise $\mathrm{RE}^{2}$, any project team should be able to work seamlessly with accurate building information (e.g. plans, material, etc) on a digital and common platform called Building Information Modelling (BIM) (BIS, 2012; Bryde et al., 2013). This project explores modern imaging technology for the efficient provision of such digital information.

BIM has the potential to achieve sustainability given that it aims to provide efficient design, construction, operation and maintenance of buildings (Wong and Fan, 2013). The use of BIM was mandated for Government projects by 2016 (Cabinet Office, 2011), and valued at $£ 46$ billion between 2016-2020 (HM Government, 2014). However, a BIM readiness report indicated that $73 \%$ of built environment Small and Medium Enterprises (SMEs) have never worked with BIM models (NFB, 2012) and SMEs represent an $85 \%$ share of employment in the construction industries private sector (BIS, 2013). BIM models are not just 3D drawings, they allow project team members to add, edit, delete and share real-time information and design specifications using a common data interchange platform. They can also integrate and combine files from alternative computer-aided design software (e.g. Autodesk Revit, Graphisoft ArchiCAD, Bentley Architecture, etc.) into a single file format (e.g. Industry Foundation Classes (IFC)). BIM provides multi-dimensional information of buildings or structures i.e. the built environment, allowing the identification of a design collision between the multidisciplinary project team; check for accessibility compliances; capture design and material information; supply chain integration and much more.

BIM has been studied and applied to many new projects; however, it is often a problem to use it in existing buildings (e.g. refurbishment projects, facilities management, etc.) due to difficulties with the dataset that characterises the facility in question (Volk et al., 2014). Threedimensional information gathered through means of Light Detection And Ranging (LiDAR) laser scanning can help to solve this issue. LiDAR collects geometrical and spatial information 
as a $3 \mathrm{D}$ point cloud data (PCD) that can later be exported to a digital BIM model. However, the problem is that these point clouds collected from the laser scanning process are merely a representation because they do not contain any semantic information or geometrical context. This data currently has to refer to external sources i.e. manual modelling to be used in a BIM model (Jung et al., 2014). Therefore, the full potential of using this technique to implement an automated 'scan-to-BIM' process is still very much underdeveloped. The BIM implementation in existing projects is difficult and challenging due to the limited availability of data regarding the original project. This data may have been lost or damaged and the process of change management during construction, operation and maintenance may have been poor or nonexistent (Gorse and Highfield, 2009). The availability of accurate spatial and geometric information of the facilities is important for both the success of any existing building and maintenance strategies. For this reason, the potential in the use of laser scanning and digital imaging has been growing and major benefits can be obtained by applying these technologies (Goedert et al., 2008; Tang et al., 2010).

Despite being voluntary, there is an increasing trend in certifying buildings under sustainability assessment schemes (Lee, 2013). These are widely used as an instrument to achieve reductions in the environmental impacts caused by buildings. BREEAM, LEED, CASBEE, BEAM Plus, GBLS, Green Star, HQE, Green Mark, GBI and MyCrest are assessment schemes (discussed further in Section 4) which have been applied successfully to many projects, but most were not designed to assess existing buildings. It was previously mentioned that laser scanning can be used to collect existing parametric building data as point clouds, which can be used for modelling of energy consumption, comfort and costing. A summary of the relevant previous studies is tabulated in Table 1, which included the contribution and limitation of these studies. Based on these previous studies, it is found that the linkage between the laser scanning, BIM and sustainability assessment is missing. Therefore, the aim of this paper is to review the process flow in the application of laser scanning for existing buildings and its surrounding built environment to support building sustainability assessment schemes. The paper is structured as follows: first, laser scanning in the built environment is explained to understand how it works and to connect this area with the rest of the topics covered. A description on scan-to-BIM is also provided, and finally the link with assessment schemes is established to present the process flow and its components.

\section{Insert Table 1}

\section{Laser scanning in the built environment}

Datasets from the laser scanner record real-world objects (e.g. existing buildings, facilities, construction sites, etc.), collecting data of their geometry, which can be used to construct digital models that can be used for a wide range of applications (Georgopoulos et al., 2010). Building surveying, structural engineering, transportation, construction design and existing buildings are some of the fields that have seen benefits from the use of this technology. Interest in laser scanning has been growing and established in the industry as a tool to generate 'as-built' conditions of existing facilities (Randall, 2011; Tang et al., 2010). The LiDAR scanning 
process works is by capturing object coordinates; longitude, latitude and elevation in reference to the scanner's location. In order to obtain the correct amount of data, it is a common practice to scan the object from different locations as demonstrated in Figure 1.

\section{Insert Figure 1}

The method to implement a scan-to-BIM process can be broken down into three steps that start with the data collection. Here the geometric data is collected using multiple laser scans from different reference locations. Then data pre-processing correlates the different PCDs obtained from the multiple laser scans, removing noise and integrating the data into a single dataset with common a Cartesian coordinate system. Finally, various information could be incorporated within the single model to create semantically rich BIM (Tang et al., 2010). In general, laser scanning techniques are used for measuring infrastructure and building dimensions and for recording and updating city surfaces (Tang and Akinci, 2012). Stakeholders can also visualise building conditions and performance before construction and design decisions can be made regarding environmental impacts, and how to manage them. This process is performed by using BIM and is predominantly used in the design of new buildings. Table 2 summarises the relevant previous studies in focusing on the application of laser scanning. Most of the related studies focused on heritage buildings and infrastructure works. However, little attention has been paid to existing buildings, which hold great potential for improvement in $\mathrm{RE}^{2}$ applications. A continuous issue is data management and the change control processes used especially postconstruction and handover. Collecting as-built conditions and obtaining as-is energy information of the building is a time consuming, costly and slow process. Different modellers creating the same building with the same tools can vary energy assessments because the analysis is often arbitrary in practice (Bazjanac, 2010).

Laser scanning technology is of great help to obtain as-built BIM models but with the difficulty of that of the process of converting the measured PCD to a BIM model. Missing information of the facility due to the amounts of data is still provided through manual modelling techniques (Wang and Cho, 2015). Post-processing is required to reach the full potential of the BIM model (Laing et al., 2015). Figure 2 illustrates raw PCD from laser scanning of the Cheong Fatt Tze Mansion in Penang, Malaysia. From this dataset little can be achieved as point clouds are only points in a Cartesian space: making the PCD intelligent is the way forward.

\section{Insert Table 2}

Insert Figure 2

\section{Scan-to-BIM}

Scan-to-BIM is often spoken as the mantra to solve the built environment's problems for RE ${ }^{2}$ projects. Figure 3 demonstrates scan-to-BIM flow by stating its applications, advantages and disadvantages. Many practitioners draw lines and 'join the dots' in PCD to produce BIM models. PCD must be manually converted into in 3D models and manually associated with the 
information on material, dimensions, etc. to create BIM models. This is often much too tedious and time-consuming, allowing for high user errors and incorrect information (Jung et al., 2014). Current research uses 2D imaging and 3D borders to identify object edges to generate BIM models, but have largely failed. Xiong et al. (2013) argued the need to identify and model the main visible structural components of an indoor environment (e.g. walls, doors, ceilings, windows and doorways), and to improve the boundary accuracy and incorporate colour and laser reflectivity information. Volk et al. (2014) reported the challenges of capturing structural, concealed or semantic building information under changing environmental conditions; and transforming captured data into semantic BIM objects and relationships. Jung et al. (2014) explored manual construction of the as-built BIM and discovered surface boundaries were not clear, manifesting as irregularly zigzagged shapes due to imperfect segmentation; and in practice, noise removal is unexpectedly time-consuming. Dimitrov and Golparvar-Fard (2014) generated a semantically-rich model and achieved 97\% accuracy for specific material recognition. However, no research has produced beyond geometrical information, material and spatial relationship/interconnectivity among elements (eg. beam supported by a column) from PCD, and beyond.

In Europe, most of the residential projects were created before 1990 (BPIE, 2011) and do not have associated information documentation expressed in a BIM model (Arayici, 2008; Armesto et al., 2009). The scan-to-BIM process can be a potential solution. However, the process is costly and manual input is still required (Valero et al., 2011; Klein et al., 2012). Even though it is not yet possible to automate the transferring of information from PCD into the BIM model, it is possible to develop a work breakdown structure where automation can be planned to maximise efficiency gains. However, there are still some issues that need to be addressed and more knowledge is required (Laing et al., 2015). Despite these disadvantages, research is indicating that scan-to-BIM automation is a potentially robust method, providing an easier process and avoiding the problems manual modelling of information can cause.

To produce models for existing buildings and their built environment, the interior and exterior can be scanned. Using PCD and 2D images users must generally take an educated guess of the material, object or element of the building. Automated scan-to-BIM has been studied intensely and recent research shows that it is possible to recognise aspects such as secondary building components (Adán et al., 2018) and Mechanical Electrical and Plumbing (MEP) cylindrical components (Bosché et al., 2015) which can be later translated to a BIM model. Another similar use is in progress monitoring, where Rebolj et al. (2017) proposed a scan-to-BIM method to support automated monitoring of construction processes aiming to identify and report delays in the scheduled plan.

The pressures of sustainable living will revolutionise building design and economic growth created in cities will increase pressure to accommodate the expanding business and population needs. Existing buildings, not new, hold this strategic role. This is an opportunity to take control to improve environmental sustainability, cut carbon emissions and increase building affordability from existing buildings.

\section{Insert Figure 3}




\section{Building sustainability assessment schemes}

Building sustainability assessment schemes are considered one of the effective means to measure and improve the performance of buildings by using a set of criteria and targets in order to achieve higher environmental standards. Thus, a number of rating tools have been developed across various regions to provide an appropriate platform for managing environmental problems in the built environment. The Building Research Establishment Environmental Assessment Methodology (BREEAM) is one of the prominent assessment schemes for evaluating the sustainability performance of new and existing buildings. The new BREAAM Refurbishment and Fit-out was produced in 2015 to assess the level of refurbished building sustainability (BREEAM, 2015). In the United States, Leadership in Energy and Environmental Design (LEED) is another leading scheme that widely adopted in various countries such as China, Canada, Brazil and India (Lee, 2013; Darko and Chan., 2016). LEED applies to new buildings, existing buildings, interiors and neighbourhood development. Other prominent sustainability schemes include the Building Environmental Assessment Method (BEAM) used in Hong Kong, Green Building Labelling System (GBLS) in Taiwan, Comprehensive Assessment System for Built Environment Efficiency (CASBEE) in Japan, Haute Qualité Environnementale (HQE) rating system in France and many others.

In order to support building assessment for existing buildings, laser scanning enables building geometry to be captured in detail with rich information for digitalisation and modelling purposes. Data for existing buildings and the wider built environment can be gathered such as thermal insulation of the building, ventilation and air-conditioning, and building condition although not efficiently. This data allows for simulation and visualisation in a BIM model to generate and evaluate different sustainable solutions. Efficient design can be achieved by using modelling features by considering building massing, building envelope, building orientation and energy modelling (Abanda and Byers, 2016). Many analysis tools are available for building performance analysis which can be integrated into building models for performing different functions such as whole-building energy analysis, water usage, lighting, acoustic examination and thermal analysis. Under such conditions, energy-saving, and carbon reduction can be achieved by performing a detailed analysis, which enables performance prediction (Abanda and Byers, 2016) and optimum choices of $\mathrm{RE}^{2}$ by using BIM. Cepurnaite et al. (2017) articulated that the digitalisation of the building refurbishment process should include energysaving measures. To support this, many previous studies by Khaddaj and Srous (2016), Wang and Cho (2015) and Sanhudo et al. (2018) have conducted research in using BIM and laser scanning for energy retrofitting purposes.

Building behaviours and performance can be simulated using BIM by considering building orientation, temperature, lighting, occupancy, and type of activities. Thus, occupants' comfort and health can be considered during modelling. For instance, thermal modelling and analysis can be carried out through BIM to demonstrate how the building can be designed to maintain a comfortable operational environment for the occupants. Moreover, the cost required for each 
design alternatives can be compared to achieve cost efficiency. The quantification of each option is important for prioritisation of retrofit measures (Sanhudo et al., 2018). The quantitative results obtained can be used to evaluate the payback of various green building solutions (Wang et al., 2015). Thus, by using BIM, the results obtained allow the project team to analyse the design or refurbishment options to optimise cost and environmental impacts. In turn, the analysis results can be linked to building assessment schemes for performance determination.

The information obtained through this analysis can be used to validate the points and credits required by green building rating tools such as BREEAM and LEED. For instance, one of the important assessment criteria's is energy and it is covered in most of the assessment schemes. By carrying out whole-building energy analysis, the amount of energy reduction can be calculated and quantified which in turn could determine the assessment credits awarded. The analysis will guide the selection of the most suitable and best energy-efficient solutions to improve the performance of the building. Various retrofitting measure in existing buildings can be considered by comparing before and after simulations with the possibility to calculate the assessment credits obtained (Maltese et al., 2017). It allows project members and end-users to make modifications virtually before construction begins and objectively consider the best value solutions (Abanda and Byers, 2016). It is crucial to have this data as mistakes can be avoided in the later stages of the $\mathrm{RE}^{2}$ process.

\section{Sustainability-led design scan-to-BIM process}

Sustainability-led design requires awareness of various sustainable principles and quantitative measurements in order to inform the design process of buildings refurbishment. For existing buildings, where sustainable principles were not a core element of the original design process, significant financial and time investment is required to enable the whole-life cycle assessment of the refurbishment project. In sustainability-led design sustainability is the measurement of quality for the project and sits at the centre of a project's triple constraints of cost, scope and time.

A new process in sustainability-led design via a scan-to-BIM process for existing buildings may provide significant potential for the built environment industry. This automated process could reduce man-hours in data collection, providing precise geometric data and accurate material detection via BIM. This can further lead to intelligent sustainability-led design options based on a whole-life cycle of systems and materials. Creating an accurate BIM model is essential. Without an accurate model, simulation modelling (e.g. energy, thermal, acoustics, fire, etc.) will be worthless. In addition, recent developments in computational technologies in both software and hardware, such as smart sensing, artificial intelligence and deep learning neural networking, big data processing, miniaturization of imaging devices, expansion of data storage and cloud computing are all applicable to data processing for the sustainable BIM model Bilal et al., 2016; Han et al., 2018; Wahabzada et al., 2015). This section introduces one 
of the approaches to extract target objects to simulate the sustainability-led design via a scanto-BIM process, as shown in Figure 4.

\section{Insert Figure 4}

Spectral properties of objects such as their spectral reflectances provide essential information about their identity. Hyperspectral digital imaging (HSI) can be used to obtain the spectral data of objects in a scene. Post image-data processing estimates the spectral surface reflectances of each pixel across various wavelengths while removing unwanted noise. An advantage of using surface reflectances is that it allows the identification of materials independently of scene illumination and environment conditions. If the radiation arriving at the imaging sensor is measured over a sufficiently broad spectral band and if the number of spectral channels is narrowly tuned, the resulting spectral signature can be used to gain accurate identification of an objects features and the material composition. Furthermore, discriminating them from among different classes of materials (Amano et al., 2018). Such an assessment is not possible by human eyes or the red-green-blue (RGB) camera with the three channels.

Figure 3 presents the various steps in enabling sustainability-led design scan-to-BIM process. Described in detail below an overview of the stages are, Stage 1.1 (S1.1) involves laser scanning and/or photogrammetry to acquire geometric data and Stage 1.2 (S1.2) acquires spectra data through RGB and HSI images. Datasets from both stages are cleaned before processing to the next step. Stage 2.1 (S2.1), where edge detection and image segmentation are applied through edge classification algorithms using both geometric and spectral datasets. Stage 2.2 (S2.2) will process and identify the spectra of individual pixels through a spectral database. The combination of S2.1 and S2.2 will create BIM objects, and multiple BIM objects will create a BIM model (Stage 3 ) of any existing facility.

Once the model is available and verified, design simulation can begin. Stage 4.1 (S4.1) will simulate the selected environmental scheme credits (e.g. BREEAM, LEED) and Stage 4.2 (S4.2) will gain material embodied energy information from a supplier database (e.g. Publicly Available Specification (PAS) 2050, Environmental Product Declaration (EPD)). Stages S4.1 and S4.2 must work together in order to identify the best sustainability options through the whole lifecycle assessment of materials used and not just consider 'in-use' energy consumption. Upon completion, existing facilities have the option to be truly sustainable through sustainability-led design simulation. Further explanation of each stage is as below:

S1.1 - The acquisition of spatial geometric data of the existing facilities can be undertaken using a laser scanner or photogrammetry techniques. Laser scanners can produce a model with measurement accuracies of $\pm 2 \mathrm{~mm}$ for distances of over 250 meters but only at 'line-of-sight'. Difficult or inaccessible areas, such as rooftops or intricate designs require photogrammetry techniques however accuracy is only up to $\pm 10 \mathrm{~mm}$. Laser scanning and photogrammetry can be combined to produce a complete geometrical model from PCD. 
S1.2 - Most of the terrestrial laser scanners available in the market are capable of acquiring high-resolution PCD and RGB images simultaneously and provide automatic integration of the two data sets. A hyperspectral camera can be operated with the laser scanner at the same time to acquire HSI images. It should be noted that PCD does not contain any semantic information but merely geometrical coordinates and intensity values per point. The integration of PCD to the RGB colour images is one way to address this problem. Scanners predominately use their own proprietary software to integrate the colour images to PCD. However, there are critical limits in the RGB image, such as the lack of sensor calibration and metamerism. To overcome the issues, a further integration to the spectral image of the identical scene is considered (Amano et al., 2018). Conventional or advanced image processing techniques of the image registration can be applied between the RGB image and the spectral reflectance image.

S2.1 - RGB image edge detection algorithms are well established and commonly used to identify or extract edge features of an image. Similarly, HSI images can also be used for geometric information and edge detection. Datasets with simultaneous PCD and RGB images can now be separated into individual objects. S2.1 and S2.2 crossover will enable HSI and RGB images to be used independently or integrated for geometric and material information.

S2.2 - The spectral reflectances of the target areas are compared with the hyperspectral spectra database, which is a collection of building and construction materials. Spectral characteristics of urban construction materials, such as an ageing effect on concrete and clay tiles, have been examined to establish a spectral library for the BIM (Nasarudin and Shafri, 2011). It has been also the case for the spectral characteristics of asphalt road ageing and deterioration (Herold and Roberts, 2005; Mei et al., 2014). This data provides the important evidence that the spectral characteristics and their examination need to be considered to identify both new and aged materials. In the case of heritage buildings, it is possible that the materials may be unknown, hence, extra surveys and tests will be required to identify the materials. Individual objects are now identified with geometric and material information - to be verified before a new BIM object is created.

S3 - Multiple BIM objects are now verified to be part of the BIM model of an existing facility. This model will now have accurate geometrical and material information. The model must now undergo a verification process to ensure the new BIM model is the exact representation of the existing facility.

S4.1 - With the new BIM model, sustainability-led design simulations can now start. Environmental schemes can be selected to be simulated, e.g. BREEAM Refurbishment or CASBEE, where sustainability credits/scores can be given. Here, building performance can be simulated with various design options and material information.

S4.2 - Material information can be better identified and used for the model simulation. EPD calculates energy and emissions from raw material extraction, transport, manufacture, assembly, installation as well as disassembly, deconstruction, and decomposition, which is a verified and registered document that communicates transparent and comparable information 
about the life-cycle environmental impact of products (PAS2050:2010). There is a need to calculate embodied carbon emissions of construction and building products, as these represent up to $70 \%$ of all carbon emissions (depending on building type), with operational carbon only 30\% (Lou et al., 2017; Pomponi and Moncaster, 2016). Embodied carbon, as well as other environmental performance indicators, are reported in EPDs.

\section{Discussion}

A large number of previous studies focused on discussing the application of 3D scanners and BIM in building refurbishment. For instance, Cepurnaite et al. (2017) discussed the benefits of using BIM and 3D scanning technology to digitalise the building refurbishment process. Patraucean et al. (2015) and Tang et al. (2010) presented an overview of the as-built modelling process by focusing on the data modelling stage. Jung et al. (2014) suggested a semi-automatic approach in view of the limitation of fully automated as-built BIM creation. On the other hand, Khaddaj and Srous (2016) examined the application of BIM to retrofit existing buildings for reducing energy consumption, whereas Cho et al. (2015) gave an overview on the state-of-theart technologies for existing building diagnostic to implement energy-efficiency measures. Wang and Cho (2015) also proposed a framework to determine energy retrofit for existing buildings by using 3D LIDAR scanner to create as-is BIM for building performance analysis. Similarly, a BIM-based systematic approach was proposed by Sanhudo et al. (2018) for energy retrofitting. Most of the previous studies managed to demonstrate the application of BIM and 3D scanning for buildings refurbishment by focusing on scanning, modelling the information and assessing the building performances. Despite this, the approach to sustainability rating by using assessment schemes is missing. Moreover, most of the studies focused on energy retrofitting, but sustainability is not limited to save energy and reduce $\mathrm{CO}_{2}$ emission. It includes other important criteria such as improve indoor environmental quality, water saving, reduce waste production and others (Rodger et al., 2019). Sanhudo et al. (2018) highlighted that energy retrofitting is one of the small topics within retrofitting, broader scope of the retrofitting should be considered. Thus, the proposed sustainability-led design scan-to-BIM process aims for broader aspects of assessment in all related criteria, not limited to energy criteria only.

As compared with previous studies, the novelty of this research lies in the integration of laser scans, hyperspectral imaging, BIM and sustainability assessment to virtually investigate the impact of $\mathrm{RE}^{2}$ options. It aims to help to achieve sustainability of existing buildings by demonstrating the whole process from data acquisition, modelling and simulation for performance in order to achieve sustainability ratings. Adopting a rating tool enable the calculation assessment criteria at the early design stages which could allow for sustainable design (Maltese et al., 2017). It is known that most of the existing buildings are not built and maintained sustainably (Kamaruzzaman et al., 2019). Thus, it is necessary to ensure that such buildings could be refurbished and/or upgraded to meet the required performance standards using appropriate assessment schemes. The performance of refurbished buildings should evaluate by appropriate assessment tools to ensure sustainability. It will defeat the sustainability purpose if the performance of refurbished buildings didn't meet the standards 
and requirements as defined in the rating tools. Thus, the benefits of sustainability-led design scan-to-BIM process include:

- Support information creation, modelling, storage and visualization for retrofitting.

- Perform multiple simulation and analysis instantly of various retrofitting measures at the beginning stage.

- Predict the sustainability performance of refurbished building with assessment rating tools.

- It enables a well-informed decision-making process regarding refurbishment options and choices, from data acquisition, building modelling and analysis, and finally performance assessment by using designed assessment schemes.

However, the use of laser scanning imposes considerable limitations on implementing these technologies. Firstly, information on the higher parts of the buildings and its built environment, such as the surface of the roof, edge and corner of the objects, and hidden areas that blocked by trees or other buildings can be difficult to scan. Incomplete data can reduce the accuracy which in turn affects the building performance simulation for sustainability assessment. This can be solved through the use of photogrammetry techniques and images but with lower quality and resolution. Next, there are some materials are difficult to identify due to age and building degradation. The materials might no longer be in production and available in the market, hence it is difficult to be defined by HSI analysis. The critical issue for 3D scanning would be the identification and classification of objects and materials in the point cloud (Amano et al., 2018). Furthermore, Han and Golpavar-Fard (2015) discovered that thermal properties and values of building elements and materials will be diminished due to deterioration. However, the thermal properties in the HSD database are often dedicated to new building elements without considering the deterioration. Thus, the lack of updates of material properties may cause inaccurate simulations due to value deviation which provides false energy performance data and eventual misguided building retrofit decisions.

The integration of the 3D point cloud with 2D spectral images is theoretically feasible (Amano et al., 2018), and demonstrated in other research disciplines, such as characterisation of plants and plant disease detection (Behmann et al., 2014) and examination of cultural heritage objects and buildings (Granero-Montagud et al., 2013). Further, a new computational image fusion method between the 3D point cloud and 2D colour image data has been proposed (Tamas and Kato, 2013), where the characterisation of the imaging devices is required. The camera calibration is considered as a necessary step in the $3 \mathrm{D}$ computer vision to extract metric information from 2D images (Zhang, 2000). It estimates intrinsic and extrinsic parameters. The intrinsic parameters are the internal characteristics of the imaging device, such as focal length, skew, distortion, and image centre. The extrinsic parameters describe its position and orientation in the world (coordinates). Knowing these parameters is essential, as it allows estimating the scene's structure in Euclidean space and removes lens distortion, which degrades accuracy. However, there are certain practical disadvantages, particularly in the proposed method (Amano et al., 2018). 
Since spectral properties are concerned, the physical characteristics of light must be considered, namely, chromatic aberration. The correction of the chromatic aberration is necessary to achieve accurate identification and classification. The correction can be made in the post image processing (for example, the image registration across the spectral channels) or using specially designed optical devices (for example, an achromatising lens). Limitation of the sustainabilityled design scan-to-BIM process include:

- Access to rich data where a limited field of view is present in complex and narrow areas.

- Dynamically adjusting the spectral scanning range required depending on the materials in view.

- How to manage unknown materials within a data set without loss of information.

- Construction and building materials may be site (region) specific (culture and history), in particular for the heritage buildings.

- Calibration of various imaging systems. As well as the hyperspectral imaging, there are approximations with the modified RGB camera or multispectral imaging available.

- Environmental effects such as lighting, shadow, sky, secularity, mutual reflection, movement, weather.

- High demands in computational power and data storage, although modern Field Programmable Gate Array, CUDA, and distributed computing could provide a solution (Georgis et al., 2016; Szydzik et al., 2011).

\section{Conclusion}

$\mathrm{RE}^{2}$ of existing buildings using laser scanning and BIM will have a strong influence on the initiatives taken by the communities to reduce $\mathrm{CO}_{2}$ emission and global warming. The sustainability agenda is now rapidly influencing architectural, construction and engineering sectors. However, it is notable that most of the targets have been predominantly for new buildings. Less attention has been dedicated to existing buildings, despite existing buildings forming a larger portion of the total supply and contributing significantly to energy consumption. Although the benefits of using BIM are well-known in the industry, the link between BIM and sustainability for existing buildings and refurbishment is sparse and limited in application.

This research suggested a viable process for sustainability-led design scan-to-BIM in existing buildings for $\mathrm{RE}^{2}$ processes. The digital models allow various technical and environmental parameters to be included for performance simulation and analysis which in turn could achieve sustainability performance assessed by a suitable rating tool. The use of laser scanning can automate the process of capturing as-built information which can then be integrated into BIM databases. It is still possible to adopt traditional methods for documenting the drawings and information of existing buildings, however, it is the efficiency and ease that means this method was adopted as an industry standard. Current methods of Sustainability-led design in the refurbishment of existing buildings are no longer fit for purpose. 
The incorporation of laser scanning and hyperspectral images can enhance the process in term of time saving but most importantly accuracy. With the help of laser scanning and a hyperspectral camera as an expeditious method of obtaining accurate an consistent, quantifiable data and information pertaining to the existing buildings. The contextualised rich data obtained can be used to create efficient design alternatives in a quick and cost-effective way supporting the entire modelling stage. The accuracy of the collected information directly affects the reliability of the analysis for the retrofit process which as discussed is an already poor process. A sustainability-led scan-to-BIM process offers potential as a robust solution to these $\mathrm{RE}^{2}$ processes.

However, using laser scanning and BIM tools to achieve sustainable goals of building refurbishment encounters several challenges as summarised in this research. In future work, the proposed sustainability-led design scan-to-BIM will be implemented on existing buildings to demonstrate the process of achieving sustainability performance in existing buildings. From that, the results obtained could be used to enhance the robustness of the proposed process.

\section{Acknowledgements}

This research is supported by BECAS Chile (Folio 72170109), National Commission for Scientific and Technological Research (CONICYT), Ministry of Education, Chile. We would also like to thank Mr Laurence Loh of LLA Architects Malaysia for access to the Cheong Fatt Tze Mansion in Penang, Malaysia.

\section{References}

Abanda, F.H., Byers, L. (2016). An investigation of the impact of building orientation on energy consumption in a domestic building using emerging BIM (Building Information Modelling). Energy, 97, 517-527.

Adán, A., Quintana Galera, B., Prieto, S., Bosché, F. (2018). Scan-to-BIM for 'secondary' building components. Advanced Engineering Informatics, 37, 119-138.

Amano, K., Lou, E.C.W. \& Edwards, R. (2019). Integration of point cloud data and hyperspectral imaging as a data gathering methodology for refurbishment projects using building information modelling (BIM). Journal of Facilities Management, 17(1), 57-75.

Amano, K., Lou, E.C.W., \& Edwards, R. (2018). BIM for Existing Facilities: Feasibility of Spectral Image Integration to 3D Point Cloud Data. Journal of Facilities Management. Retrieved from https://doi.org/10.1108/JFM-11-2017-0064

Arayici, Y. (2007). An approach for real world data modelling with the 3D terrestrial laser scanner for built environment. Automation in Construction, 16, 816-829.

Arayici, Y. (2008). Towards building information modelling for existing structures. Structural Survey, 26(3), 210-222.

Argüelles-Fraga, R., Ordóñez, C., García-Cortés, S., \& Roca-Pardiñas, J. (2013). Measurement planning for circular cross-section tunnels using terrestrial laser scanning. Autom. Const., 31, 1-9. 
Armesto, J., Lubowiecka, I., Ordonez, C., Rial, F.I. (2009). FEM modeling of structures based on close range digital photogrammetry. Automation in Construction, 18(5), 559-569.

Armesto-González, J., Riveiro-Rodríguez, B., González-Aguilera, D., \& Rivas-Brea, M.T. (2010). Terrestrial laser scanning intensity data applied to damage detection for historical buildings. Journal of Archaeological Science, 37, 3037-3047.

Aydin, C. C. (2014). Designing building façades for the urban rebuilt environment with integration of digital close-range photogrammetry and geographical information systems. Autom. Constr., 43, 38-48.

Bazjanac, V. (2010). Space Boundary Requirements for Modeling of Building Geometry for Energy and Other Performance Simulation. Paper presented at the 27th CIB-W78 Conference, 16-18, Cairo, Egypt.

Behmann, J., Steinrücken, J., Plümer, L. (2014). Detection of early plant stress responses in hyperspectral images. ISPRS Journal of Photogrammetry and Remote Sensing, 93, 98-111.

Bilal, M., Oyedele, L.O., Qadir, J., Munir, K., Ajayi, S.O., Akinade, O.O., Owolabi, H.A., Alaka, H.A., Pasha, M. (2016). Big Data in the construction industry: A review of present status, opportunities, and future trends. Advanced Engineering Informatics, 30(3), 500-521.

BIS. (2012). Building Information Modelling, Department of Business Innovation and Skills, London, UK.

BIS. (2013). Business population estimates for the UK and regions 2013, Department of Business Innovation and Skills, London, UK.

Bosché, F. (2010). Automated recognition of 3D CAD model objects in laser scans and calculation of as-built dimensions for dimensional compliance control in construction. Adv. Eng. Inform, 24, 107-118.

Bosché, F., Ahmed, M., Turkan, Y., Haas, C., \& Haas, R. (2015). The value of integrating Scan-to-BIM and Scan-vs-BIM techniques for construction monitoring using laser scanning and BIM: The case of cylindrical MEP components. Automation in Construction, 49 (Part B), 201-213.

BPIE. (2011). Europe's Buildings under the Microscope: A Country-by-Country Review of the Energy Performance of Buildings, Buildings Performance Institute Europe (BPIE), Brussels, Belgium.

BREEAM. (2015). BREEAM International Refurbishment and Fit-out. Retrieved from http://www.breeam.com/refurbishment-and-fit-out

Bryde, J., Broquestas, M., Volm, J.M. (2013). The project benefits of Building Information Modelling (BIM). International Journal of Project Management, 31(7), 971-980.

Cabinet Office. (2011). Government Construction Strategy, London, UK.

Cepurnaite, J., Ustinovicius, L., \& Vaisnoras, M. (2017). Modernization with BIM technology through scanning building information. Procedia engineering, 208, 8-13.

Cepurnaite, J., Ustinovicius, L., Vaisnoras, M. (2017). Modernization with BIM technology through scanning building information. Procedia Engineering, 208, 8-13.

Cho, Y. K., Ham, Y., \& Golpavar-Fard, M. (2015). 3D as-is building energy modeling and diagnostics: A review of the state-of-the-art. Advanced Engineering Informatics, 29(2), 184-195.

Darko, A., Chan, A.P. (2016). Critical analysis of green building research trend in construction journals. Habitat International, 57, 53-63.

Dimitrov, A., Golparvar-Fard, B. (2014). Vision-based material recognition for automated monitoring of construction progress and generating building information modeling 
from unordered site image collections. Advanced Engineering Informatics, 28(1), 3749.

Edwards, J., Townsend, A. (2011). Buildings under refurbishment and retrofit, Carbon Action 2050 White Papers, Charted Institute of Building (CIOB), United Kingdom.

Edwards, R., Lou, E., Bataw, A., Kamaruzzaman, S.N., \& Johnson, C. (2019). Sustainabilityled design: Feasibility of incorporating whole-life cycle energy assessment into BIM for refurbishment projects. Journal of Building Engineering, 24, 100697.

Georgis, G., Lentaris, G., Reisis, D.J. (2016). Acceleration techniques and evaluation on multi-core CPU, GPU and FPGA for image processing and super-resolution. Journal of Real-Time Image Processing, 1-28.

Georgopoulos, A., Ioannidis, C., Valanis, A. (2010). Assessing the Performance of A Structured Light Scanner, International Archives of Photogrammetry, Remote Sensing and Spatial Information Science, XXXVIII (5), 251-255.

Goedert, J.D., Meadati, P. (2008). Integrating Construction Process Documentation into Building Information Modeling. Journal of Construction Engineering and Management, 134, 509-516.

Gorse, C., Highfield, D. (2009). Refurbishment and Upgrading of Buildings, 2nd edn. Abingdon, England: Spon Press.

Granero-Montagud, L., Portalés, C., Pastor-Carbonell, B., Ribes-Gómez, E., Gutiérrez-Lucas, A., Tornari, V., Vassilis, V., Groves, R.M., Sirmacek, B., Bonazza, A., Ozga, I., Vermeiren, J., van der Zanden, K., Föster, M., Aswendt, P., Borreman, A., Ward, J.D., Cardoso, A., Aguiar, L., Alves, F., Ropret, P., Luzón-Nogué, J.M., Dietz, C. (2013). Deterioration estimation of paintings by means of combined $3 D$ and hyperspectral data analysis, Paper presented at Proceedings of the SPIE 8790, Optics for Arts, Architecture, and Archaeology IV, 879008.

Haddad, N.A. (2011). From ground surveying to 3D laser scanner: A review of techniques used for spatial documentation of historic sites. Journal of King Saud University Engineering Sciences, 23(2), 109-118.

Han, K., Degol, J., Golparvar-Fard, M. (2018). Geometry- and Appearance-Based Reasoning of Construction Progress Monitoring. Journal of Construction Engineering and Management, 144(2), 04017110.

Herold, M., Roberts, D. (2005). Spectral characteristics of asphalt road aging and deterioration: implications for remote-sensing applications. Applied Optics, 44(20), 4327-4334.

HM Government. (2014). Government construction pipelines spreadsheet, July 2014 update, Retrieved from http://s3.amazonaws.com/academia.edu.documents/31059489/CRE SINTERECPAPER.pdf?AWSAccessKeyId=AKIAJ56TQJRTWSMTNPEA\&Expires $=1443633496 \&$ Signature $=\mathrm{k} 5 \mathrm{aCN} 2 \mathrm{DTW}$ J JnmhxTCqfHyD8Qbwc\%3D\&responsecontent-disposition=inline.

Huang, L., Krigsvoll, G., Johansen, F., Liu, Y., Zhang, Z. (2018). Carbon emission of global construction sector. Renewable and Sustainable Energy Reviews, 81, 1906-1916.

IPCC. (2007). Climate Change 2007 Synthesis Report, Intergovernmental Panel on Climate Change (IPCC), Geneva, Switzerland.

Jung, J., Hong, S., Jeong, S., Kim, S., Cho, H., Hong, S., Heo, J. (2014). Productive modeling for development of as-built BIM of existing indoor structures. Automation in Construction, 42, 68-77.

Kamaruzzaman, S.N., Lou, E.C.W., Wong, P.F., Edwards, R., Hamzah, N., Ghani, M.K. (2019). Development of a non-domestic building refurbishment scheme for Malaysia: A Delphi approach. Energy, 167, 804-818. 
Kazuaki Kawashima, K., Kanai, S., \& Date, H. (2014). As-built modelling of piping system from terrestrial laser-scanned point clouds using normal-based region growing. Journal of Computational Design and Engineering, 1(1), 13-26.

Khaddaj, M., \& Srour, I. (2016). Using BIM to retrofit existing buildings. Procedia Engineering, 145, 1526-1533.

Kim, C., Son, H., \& Kim, C. (2013). Automated construction progress measurement using a 4D building information model and 3D data. Autom. Constr., 31, 75-82.

Klein, L., Li, N., Becerik-Gerber, B. (2012). Imaged-based verification of as-built documentation of operational buildings. Automation in Construction, 21(1), 161-171.

Kylili, A., Fokaides, P.A., Jimenez, P.A.L. (2016). Key Performance Indicators (KPIs) approach in buildings renovation for the sustainability of the built environment: A review. Renewable and Sustainable Energy Reviews, 56, 906-915.

Laing, R., Leon, M., Isaacs, J., Georgiev, D. (2015). Scan to BIM: the development of a clear workflow for the incorporation of point clouds within a BIM environment. WIT Transactions on the Built Environment, 149, 279-289.

Lee, W.L. (2013). A comprehensive review of metrics of building environmental assessment schemes. Energy and Buildings, 62, 403-413.

Li, S., Isele, J., \& Bretthauer, G. (2008). Proposed Methodology for Generation of Building Information Model with Laser scanning. Tsinghua Science \& Technology, 13(Supplement 1), 138-144.

Lou, E.C.W., Lee, A., Welfie, A. (2017). Greenhouse Gas Performance of Construction Refurbishment Projects - Lessons from UK Higher Education Student Accommodation Case Studies. Journal of Cleaner Production, 154, 309-317.

Maltese, S., Tagliabue, L. C., Cecconi, F. R., Pasini, D., Manfren, M., \& Ciribini, A. L. (2017). Sustainability assessment through green BIM for environmental, social and economic efficiency. Procedia engineering, 180, 520-530.

Mei, A., Salvatori, R., Fiore, N., Allegrini, A., Andrea, A. (2014). Integration of Field and Laboratory Spectral Data with Multi-Resolution Remote Sensed Imagery for Asphalt Surface Differentiation. Remote Sensing, 6(4), 2765-2781.

Nasarudin, N.E.M., Shafri, H. (2011). Development and Utilization of Urban Spectral Library for Remote Sensing of Urban Environment. Journal of Urban and Environmental Engineering, 5(1), 45-56.

NFB. (2012). The NFB BIM-readiness survey 2012, National Federation of Builders, Sussex, UK.

Pătrăucean, V., Armeni, I., Nahangi, M., Yeung, J., Brilakis, I., \& Haas, C. (2015). State of research in automatic as-built modelling. Advanced Engineering Informatics, 29(2), 162-171.

Pesci, A., Teza, G., Bonali, E., Casula, G., \& Boschi, E. (2013). A laser scanning-based method for fast estimation of seismic-induced building deformations. ISPRS Journal of Photogrammetry and Remote Sensing, 79, 185-198.

Pomponi, F., Moncaster, A. (2016). Embodied carbon mitigation and reduction in the built environment - What does the evidence say? Journal of Environmental Management, $181,687-700$.

Randall, T. (2011). Construction Engineering Requirements for Integrating Laser Scanning Technology and Building Information Modeling, Journal of Construction Engineering and Management, 137(10), 797-805.

Raslanas, S., Stasiukynas, A., Jurgelaityte, E. (2013). Sustainability assessment studies of recreational buildings. Procedia Engineering, 57, 929-937. 
Rebolj, D., Pučko, Z., ČušBabič, N., Bizjak, M., Mongus, D. (2017). Point cloud quality requirements for Scan-vs-BIM based automated construction progress monitoring. Automation in Construction, 84, 323-334.

Sanhudo, L., Ramos, N., Poças Martins, J., Almeida, R., Barreira, E., Simões, M., Cardoso, V. (2018). Building information modeling for energy retrofitting - A review. Renewable and Sustainable Energy Reviews, 89(C), 249-260.

Shika, S.A., Sapri, M., Abdullah, S., Jibril, D., Sharil, A.R. (2012). Towards an Integrative Sustainability Concept for Retrofitting Commercial Office Buildings in Malaysia. Retrieved from http://s3.amazonaws.com/academia.edu.documents/31059489/CRESINT ERECPAPER.pdf?AWSAccessKeyId=AKIAJ56TQJRTWSMTNPEA\&Expires $=144363$ 3496\&Signature $=\mathrm{k} 5 \mathrm{aCN} 2 \mathrm{DTW}$ J JnmhxTCqfHyD8Qbwc\%3D\&response-contentdisposition=inline.

Staiger, R. (2003). Terrestrial Laser Scanning Technology, Systems and Applications, Paper Presented at Proceedings of the 2nd FIG Regional Conference, 1-10, Marrakech, Morocco.

Szydzik, T., Callico, G.M., Nunez, A. (2011). Efficient FPGA implementation of a highquality super-resolution algorithm with real-time performance. IEEE Trans. Consum. Electron., 57(2), 664-672.

Tamas, L., Kato, Z. (2013). Targetless calibration of a lidar - Perspective camera pair, Paper Presented at Proceedings of the IEEE International Conference on Computer Vision, 668-675.

Tang, P., Akinci, B. (2012). Automatic execution of workflows on laser-scanned data for extracting bridge surveying goals. Advanced Engineering Informatics, 26(4), 889-903.

Tang, P., Akinci, B., \& Huber, D. (2009). Quantification of edge loss of laser scanned data at spatial discontinuities. Autom. Constr., 18, 1070-1083.

Tang, P., Akinci, B., Huber, D. (2010). Semi-Automated As-Built Modeling of Light Rail System Guide Beams. Paper Presented at Proceedings of the Construction Research Congress 2010, Alberta, Canada.

Tang, P., Buber, D., Akinci, B., Lipman, R., Lytle, A. (2010). Automatic reconstruction of as-built building information models from laser-scanned point clouds: A review of related techniques. Automation in Construction, 19(7), 829-843.

Tapete, D., Casagli, N., Luzi, G., Fanti, R., Gigli, G., \& Leva, D. (2013). Integrating radar and laser-based remote sensing techniques for monitoring structural deformation of archaeological monuments. Journal of Archaeological Science, 40, 176e189.

Valero, E.R., Oliverm, A.A., Huber, D., Cerrada, C. (2011). Detection, Modeling and Classification of Moldings For Automated Reverse Engineering of Buildings from 3D Data, International Symposium on Automation and Robotics in Construction (ISARC), 3-8, Seoul, Korea.

Volk, R., Stengel, J., Schultmann, F. (2014). Building Information Modeling (BIM) for existing buildings - Literature review and future needs. Automation in Construction, $38,109-127$.

Wahabzada, M., Mahlein, A.K., Bauckhage, C., Steiner, U., Oerke, E.C., Kersting, K. (2015). Metro Maps of plant disease dynamics - automated mining of differences using hyperspectral images. PLoS ONE, 10(1), e0116902.

Wang, C., Cho, Y.K. (2015). Performance Evaluation of Automatically Generated BIM from Laser Scanner Data for Sustainability Analyses. Procedia Engineering, 118, 918-925.

Wang, Q., Guo, J., \& Kim, M. (2019). An Application Oriented Scan-to-BIM Framework. Remote Sens., 11(3), 365.

Wong, K., Fan, Q. (2013). Building information modelling (BIM) for sustainable building design. Facilities, 31(3/4), 138-157. 
Xiong, X., Adana, A., Akincic, B., Huberb, D. (2013). Automatic creation of semantically rich 3D building models from laser scanner data. Automation in Construction, 31, 325-337.

Xu, J., Ding, L., \& Love, P. E. (2017). Digital reproduction of historical building ornamental components: From 3D scanning to 3D printing. Autom. Constr., 76, 85-96.

Yastikli, N. (2007). Documentation of cultural heritage using digital photogrammetry and laser scanning. J. Cult. Herit, 8, 423-427.

Zhang, C., \& Arditi, D. (2013). Automated progress control using laser scanning technology. Autom. Constr., 36, 108-116.

Zhang, C., Kalasapudi, V.S., \& Tang, P. (2016). Rapid data quality-oriented laser scan planning for dynamic construction environments. Advanced Engineering Informatics, 30, 218-232.

Zhang, Z. (2000). A flexible new technique for camera calibration. IEEE Transactions on Pattern Analysis and Machine Intelligence, 22(11), 1330-1334.

Zhao, J., Zhu, N., Wu, Y. (2009). Technology line and case analysis of heat metering and energy efficiency retrofit of existing residential buildings in Northern heating areas of China. Energy Policy, 37(6), 2106-2112. 